\title{
Investigation on the Relationship of Insulin Resistance and Ketosis in Dairy Cows
}

\author{
Chuang Xu' ${ }^{1}$, Shi Shu ${ }^{1}$, Cheng Xia ${ }^{1,2 *}$, Bo Wang ${ }^{1}$, Hong-You Zhang ${ }^{1}$ and Bao Jun ${ }^{2}$
}

${ }^{1}$ Department of Clinical Veterinary Medicine, College of Animal Science and Veterinary Medicine, Heilongjiang Bayi Agricultural University, China

${ }^{2}$ Synergetic Innovation Center of Food Safety and Nutrition, Northeast Agricultural University, China

\begin{abstract}
Ketosis is an important metabolic disease of dairy cows during the transition period, but it is fully unclear about its endocrine etiology. Our study is to clarify the relationship between oxidative stress, liver function, insulin resistance and ketosis in dairy cows. Sixteen ketotic Holstein cows (T) and twenty-four non-ketotic Holstein cows (C) were used as the experimental animals from an intensive dairy farm in Heilongjiang province, China. Blood samples from all experimental cows were collected at 14 days postpartum during morning fasting. Fifteen parameters for energy balance, liver function, oxidative stress, insulin sensitivity and glucose tolerance test between $\mathrm{T}$ and $\mathrm{C}$ were measured using commercial kits. Results showed that the concentration of plasma glucose $(P<0.01)$ was lower in $\mathrm{T}$ compared with $\mathrm{C}$ cows, whereas there were marked increases in the concentration of plasma non-esterified fatty acids and beta-hydroxybutyric acid $(P<0.01)$. The level of plasma AST $(P<0.01)$, TBIL $(P<0.05)$, and DBIL $(P<0.01)$ increased significantly in T cows compared with $C$ cows, but plasma $C H E(P<0.01)$ and TP $(P<0.05)$ decreased significantly, and no significant change in plasma ALT, IBIL, ALB, and GLO. Level of plasma malondialdehyde (MDA) and superoxide dismutase (SOD) was significantly higher in ketotic cows than that of non-ketotic cows $(P<0.05)$, but value of plasma revised quantitative insulin sensitivity index (RQUICKI) was lower significantly in $T$ cows than that of $C$ cows $(P<0.05)$. Concentration of plasma $G l c$ increased significantly in $T$ cows compared with $C$ cows during glucose tolerance test $(\mathrm{P}<0.05)$. Therefore, the ketosic cows were in condition of negative energy balance, suffered to certain extent from liver function abnormality, and experienced oxidative stress and low insulin sensitivity. Therefore, a closed relationship between ketosis and insulin resistance should be related to liver function and oxidative stress that can cause insulin resistance.
\end{abstract}

Keywords: Dairy cows; Ketosis; Negative energy balance; Liver function; Oxidative stress; Insulin resistance

\section{Background}

Ketosis in dairy cows is an important metabolic disorder that easily occurs in transition period if cows cannot adapt to the high glucose demand relative to their limited intake [1]. A great amount of non-esterified fatty acids (NEFAs) from fat mobilization of dairy cows affected ketosis may produce a great deal of oxygen radical, such as reactive oxygen species (ROS) and reactive nitrogen species (RNS), which can initiate oxidative stress [2]. The oxidative stress pathway activated will prompt insulin resistance (IR), insulin secretion injury, diabetes, and vasculopathy. The common soil hypothesis was proposed by Stern [3], and just cited and "revisited" by Ceriello and Motz [4], namely the oxidative stress is a common basis of IR, diabetes and vasculopathy, which has been verified widely in clinical, but its' mechanism still is unclear. Malondialdehyde (MDA) is a degradation product of lipid peroxidation and its level in blood may be considered as an assessing indicator of lipid peroxidation degree [5]. Superoxide dismutase (SOD) is a measurable indicator of antioxidation [6]. MDA and SOD are common indicators to evaluate oxidative stress and antioxidatvie system. An unbalance happens between oxidative system and antioxiditvie system, which can cause body damaged is usually named as "oxidative stress" [7].

At present, it has been accepted nearly that euglycemic hyperinsulinemic clamp is a "golden standard" method to measure insulin resistance according to concentration of glucose and insulin in blood in animals [3,4], but it is complex, time-consuming, and expensive, So it is not usually used to investigate a herd metabolic disorder. Then some methods related closely to euglycemic hyperinsulinemic clamp, such as accurate glucose tolerance test and revised quantitative insulin sensitivity check index (RQUICKI), were established to easily assess insulin resistance, in particular RQUICKI [3,4]. In the morning, a stable balance will reach among insulin sensitivity in tissues and blood glucose, insulin, and NEFAs. It is a ready method to assess insulin resistance because of only measurement of blood glucose, insulin, and NEFAs $[4,8]$. It is not fully explicit what insulin resistance plays roles in the etiology of dairy ketosis, therefore in our experiments relationship between insulin resistance and ketosis was exploded by monitoring oxidative stress, liver function and insulin resistance in order to provide a new strategy for preventing ketosis in dairy farms in China in the future.

\section{Methods}

\section{Animals and samples collection}

All animals used in this experiment were treated according to the International Guiding Principles for Biomedical Research Involving Animals. In this study forty cows including sixteen ketotic cows (T) and twenty-four non-ketotic cows $(\mathbf{C})$, which had average of 3.6 ages, 2-3 parities, $20-30 \mathrm{~kg} / \mathrm{d}$ milk yields, and $11-16 \mathrm{~kg} / \mathrm{d}$ dry matter intake

*Corresponding author: Cheng Xia, Department of Clinical Veterinary Medicine, College of Animal Science and Veterinary Medicine, Heilongjiang Bay Agricultural University, China, Tel: +86 459-6819207; Fax: +86 459-6819207; E-mail: xiacheng2011@gmail.com

Received January 25, 2013; Accepted March 04, 2014; Published March 06 , 2014

Citation: Xu C, Shu S, Xia C, Wang B, Zhang HY, et al. (2014) Investigation on the Relationship of Insulin Resistance and Ketosis in Dairy Cows. J Veterinar Sci Technol 5: 162. doi:10.4172/2157-7579.1000162

Copyright: @ 2014 Xu C, et al. This is an open-access article distributed unde the terms of the Creative Commons Attribution License, which permits unrestricted use, distribution, and reproduction in any medium, provided the original author and source are credited. 
(DMI), were chosen around 14d postpartum from an intensive 2000 dairy cattle farm in Heilongjiang, China. The cows were considered to have ketosis if they showed clinical symptoms or no remarked signs and had plasma 3-hydroxybutyrate (BHBA) concentrations $>1.20$ $\mathrm{mmol} / \mathrm{L}$. If the cows had no clinical signs and normal plasma BHBA concentrations of BHBA concentrations $<1.00 \mathrm{mmol} / \mathrm{L}$, they were considered healthy controls $(\mathrm{C})[1,9]$. All the cows were fed a total mixed ration (TMR) at 7:00 am, 13:00pm and 19:00 pm daily during transition period, which consisted of concentrated feed, silage corn, brewer's grain, cooked soybeans, Chinese hay, melon pulp, surface melon shell, and fat. The nutritional analysis was $57.10 \%$ dry matter (DM), $18 \%$ crude protein, $7.4 \times 10^{6} \mathrm{~J} / \mathrm{kg}(\mathrm{DM})$ net energy for lactation (NEL), 5.70\% fat, 36.80\% neutral detergent fiber (NDF), 19.60\% acid detergent fiber (ADF), $0.73 \% \mathrm{Ca}$, and $0.37 \% \mathrm{P}$.

In the early morning, whole blood samples were collected from the vena caudalis mediana using sodium heparin, and then immediately centrifuged at $1,400 \times \mathrm{g}$ for $10 \mathrm{~min}$ at room temperature. The supernatants were aliquoted into Eppendorf tubes ( $1 \mathrm{~mL}$ plasma/tube) and stored at $-80^{\circ} \mathrm{C}$ until analysis. Both clinical parameters and plasma metabolites were measured for all experimental animals. Clinical blood biochemical data included glucose (Glc), $\beta$-hydroxaybutyric acid (BHBA), and nonesterified fatty acids (NEFAs) for assessing energy balance status, and aspartate aminotransferase (AST), alanine aminotransferase (ALT), total bilirubin (TBIL), direct bilirubin (DBIL), cholinesterase (CHE), total protein (TP), and albumin (ALB) for measuring liver function, and then MDA and SOD for determine oxidative stress status. All blood parameters were detected by commercial kits from Beijing Jiuqiang Biotechnology Limited Company and Shanghai Desay Diagnostic System Limited Company in China using full automatic analyzer (Hitachi 7600, Japan).

\section{Detection of insulin sensitivity detection}

According to concentration of Glc, NEFAs, and insulin (Ins) in plasma from $\mathrm{T}$ and $\mathrm{C}$, difference of insulin sensitivity index (RQUICKI) can be measured by an formula (RQUICKI $=1 /[\log G 0+\log I 0+\log$ NEFAs 0]) [4,8]. Ins was measured using ELISA kit (RD Bovine) from Nanjing Jiancheng Biotechnology Limited Company by ELISA microplate reader (HuaDong Electron DG5033A).

Seven healthy cows and nine cows with ketosis, which from the above $\mathrm{T}$ and $\mathrm{C}$ cows, were restrained at different pens respectively for one day before glucose tolerance test [10]. Each cow was administrated rapidly $1000 \mathrm{ml}$ of $50 \%$ glucose by jugular intravenous infusion for 10 $15 \mathrm{~min}$. Blood samples were collected using a catheter by jugular vein at 15 minutes before administration of glucose, and at $0,15,30,45,60,90$, 120 minutes after completion of the injection.

\section{Statistical analyses}

All numerical data from two experiments were presented as means \pm standard deviation (SD). Student's $t$-test and one-way analysis of variance (ANOVA) were used to evaluate differences between groups. In the entire research process, the significance level was set at $p<0.05$. Statistical analysis was performed using SPSS 17.0 software (SPSS Company, Chicago, IL, United States).

\section{Results}

In Table1, plasma concentrations of BHBA and NEFAs were significantly higher in $\mathrm{T}$ group than that in $\mathrm{C}$ group $(P<0.01)$. The greater values for NEFA and BHBA indicate that $\mathrm{T}$ cows were in greater negative energy balance.

\begin{tabular}{|l|c|c|c|}
\hline \multicolumn{1}{|c|}{ Parameters } & Ketosis & Control & $P$-value \\
\hline Number & 16 & 24 & \\
\hline Glc $(\mathrm{mmol} / \mathrm{L})$ & $2.70 \pm 0.89$ & $3.31 \pm 0.17$ & 0.003 \\
\hline NEFAs $(\mathrm{mmol} / \mathrm{L})$ & $0.99 \pm 0.32$ & $0.51 \pm 0.15$ & 0.000 \\
\hline BHBA $(\mathrm{mmol} / \mathrm{L})$ & $2.71 \pm 1.29$ & $0.62 \pm 0.11$ & 0.000 \\
\hline AST $(\mathrm{U} / \mathrm{L})$ & $149 \pm 40$ & $93 \pm 13$ & 0.000 \\
\hline ALT $(\mathrm{U} / \mathrm{L})$ & $22.86 \pm 4.52$ & $20.77 \pm 4.25$ & 0.171 \\
\hline CHE $(\mathrm{U} / \mathrm{L})$ & $136 \pm 17$ & $155 \pm 20$ & 0.005 \\
\hline TBIL $(\mu \mathrm{mol} / \mathrm{L})$ & $3.46 \pm 1.35$ & $2.83 \pm 0.47$ & 0.049 \\
\hline DBIL $(\mu \mathrm{mol} / \mathrm{L})$ & $2.53 \pm 0.78$ & $1.82 \pm+0.43$ & 0.001 \\
\hline IBIL $(\mu \mathrm{mol} / \mathrm{L})$ & $0.97 \pm 0.64$ & $1.04 \pm 0.51$ & 0.727 \\
\hline TP $(\mathrm{g} / \mathrm{L})$ & $73.61 \pm 3.69$ & $77.32 \pm 5.03$ & 0.023 \\
\hline ALB $(\mathrm{g} / \mathrm{L})$ & $32.48 \pm 2.29$ & $33.84 \pm 2.24$ & 0.087 \\
\hline GLO $(\mathrm{g} / \mathrm{L})$ & $41.03 \pm 3.74$ & $43.37 \pm 6.46$ & 0.228 \\
\hline SOD $(\mathrm{U} / \mathrm{mL})$ & $75.61 \pm 6.34$ & $70.11 \pm 7.86$ & 0.031 \\
\hline MDA $(\mathrm{nmol} / \mathrm{mL})$ & $2.89 \pm 0.48$ & $2.29 \pm 0.37$ & 0.047 \\
\hline Ins $(\mathrm{mlU} / \mathrm{L})$ & $13.87 \pm 1.75$ & $14.01 \pm 2.01$ & 0.043 \\
\hline RQUICKI $(\mathrm{mlU} / \mathrm{L})$ & $0.36 \pm 0.02$ & $0.38 \pm 0.02$ & 0.017 \\
\hline
\end{tabular}

*ALB, albumin; ALT, alanine aminotransferase; AST, aspartate aminotransferase BHBA, $\beta$--hydroxaybutyric acid; CHE, cholinesterase; DBIL, direct bilirubin; Glc, glucose; GLO, globulin; IBIL, indirect bilirubin; Ins, insulin; MDA, malondialdehyde; NEFAs, non-esterified fatty acids; SOD, superoxide dismutase; TBIL, total bilirubin; TP, total protein; RQUICKI, revised quantitative insulin sensitivity check index. ${ }^{* *}$ RQUICKI $(\mathrm{mlU} / \mathrm{L})=1 /[\log \mathrm{G} 0+\log 10+\log$ NEFAs0]. G0, glucose $(\mathrm{mg} / \mathrm{dl}) ; 10$, insulin ( $\mathrm{uU} / \mathrm{ml})$; NEFAs0, non-esterified fatty acids ( $\mathrm{mmol} / \mathrm{L})$

Table 1: Levels of fifteen parameters in plasma of experimented cows.

In addition, compared to $\mathrm{C}$ group, plasma levels of AST, DBIL in T group raised markedly $(P<0.01)$, and TBIL increased significantly $(P<0.05)$. Plasma concentration of CHE and TP decreased markedly in T group $(P<0.01)$. However, ALT, IBIL, ALB and GLO did not change in both groups. It suggested that there still were some abnormal changes of liver function in dairy cows with ketosis.

Furthermore, plasma concentrations of MDA and SOD were significantly higher in $\mathrm{T}$ group than that in $\mathrm{C}$ group $(P<0.01)$, RQUICKI is also lower $(P<0.05)$. It suggested that the affected cows were in condition of oxidative stress and insulin sensitivity reduced.

Finally, nine cows with ketosis were divided into two groups of T1 (5 cows) and T2 (4 cows) on the basis of plasma glucose concentration at last time. The curves of glucose tolerance test in three groups of cows shown that there were the same curve changes, and plasma Glc concentration were higher in $\mathrm{T} 1$ group than those in $\mathrm{C}$ and $\mathrm{T} 2$ groups except for $-15 \mathrm{~min}$, but similar in $\mathrm{C}$ and $\mathrm{T}$ groups except for $-15 \mathrm{~min}$ and 0 min. In Figure 1, plasma concentration of glucose in $\mathrm{T} 1$ group is significantly lower than that in $\mathrm{C}$ or $\mathrm{T} 2$ groups at 15 minutes before administration of $50 \%$ glucose, but increased markedly in T1 group at five time points after administration of $50 \%$ glucose $(P<0.05)$. Furthermore, plasma concentration of glucose in T1 group was still up to $4.24 \mathrm{mmol} / \mathrm{L}$ at $120 \mathrm{~min}$ after administration of $50 \%$ glucose $(\mathrm{P}=0.006)$. However, there were no difference in plasma concentration of glucose between $\mathrm{T} 2$ group and $\mathrm{C}$ group. It may indicate that insulin resistance exists in some cows with ketosis.

\section{Discussions}

In brief, NEFA and BHBA are products of fat catabolism that can supply energy to body. Their increased levels in blood are symbols of negative energy balance, which predict a great amount of fat mobilization [1,9]. $\beta$-oxidation of NEFA occurs mainly in liver. Its marked increase may prompt the formation of reactive oxygen species 


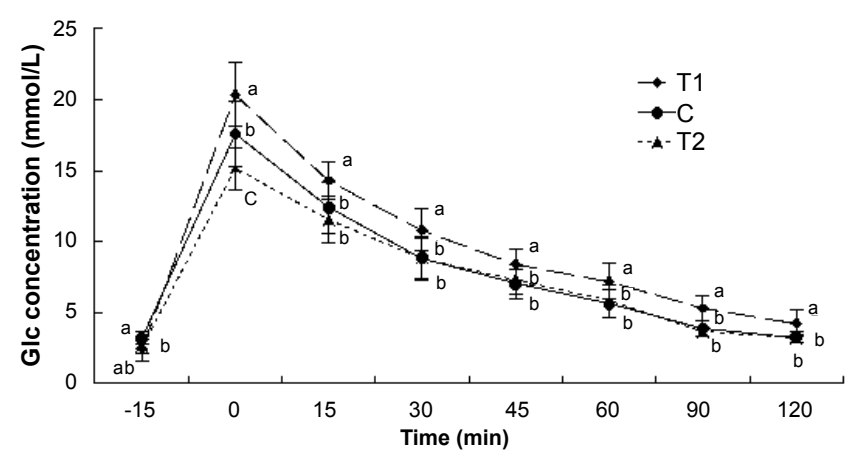

Figure 1: Glucose tolerance test curve. Seven healthy cows (C) and nine cows with ketosis $(T)$ that were divided into the high glucose (Glc) level (T1, 5 cows) and low Glc level (T2, four cows) according to plasma Glc concentration at $120 \mathrm{~min}$. Plasma Glc concentration were measured at 15 minutes before administration of glucose, and at $0,15,30,45,60,90,120$ minutes after administration of $1000 \mathrm{ml}$ of $50 \%$ glucose by jugular intravenous infusion.

(ROS) and development of oxidative stress [2,6]. Excessive NEFAs can induce oxidative stress, which is able to break down a balance between antioxidative system and oxidative system, and may inhibit glucose intake through interfering with glucose transporter function, and interfere with insulin signal transduction pathway in liver and peripheral tissues $[5,10]$. When fat mobilized greatly, accompanied by lots of NEFA, TG may accumulate in liver, and then cause fatty liver, which can damage hepatocyte $[11,12]$.

The current study showed that some parameters in plasma, such as AST, DBIL, TBIL, CHE and TP, changed significantly in cows with ketosis, suggested that liver disfunction exists in the affected cows because these abnormal parameters can reflect the abnormal status of liver function $[13,14]$. Therefore, once liver lesion for example fatty liver happens all kinds of metabolic regulation may be affected, which may induce insulin resistance, thus will affect glucose, protein and fat metabolism in dairy cows with ketosis.

In addition, in our studies the significant changes of MDA and SOD in plasma of dairy cows with ketosis indicated that the affected cows may suffer from the oxidative stress and enhance antioxidative ability. MDA has been usually used to assess oxidative stress. SOD can protect cell from oxidative lesion by catalyzing superoxide anion radical. Research $[6,15]$ suggested that there was a negative correlation between SOD and MDA, but this association between antioxidase and lipid peroxidation was not significant during early lactation. Someone observed [5,7] that the active concentration of oxidant is consistent with peak value of MDA, it is considered as an adaptation phenomenon due to an increased oxidative stress. Wang zhe et al reported that total antioxidative ability changed nonsignificantly in dairy cows affected ketosis, and mRNA expression of insulin receptor decreased $[16,17]$. There has always been no standardization to evaluate in a broken balance between oxidation and anti-oxidation in dairy cows with ketosis, so it is difficult to offer some detailed evidences on relationship of oxidative stress and ketosis $[6,8]$. Thus, in this study MDA and SOD increased markedly in dairy ketosis, suggested that cows with ketosis may experience an adaptation response to oxidative stress and antioxidation as human and rodents.

Finally, it needs a longer time to develop insulin resistance in human and rats, but insulin sensitivity changes markedly, especially from 3 weeks prepartum to 3 weeks postpartum, which is basically consistent with change of NEFA in blood $[13,18]$. In this study dairy cows with ketosis had high level of MDA and SOD, and lower RQUICKI, suggested that the affected dairy cows may have both oxidative stress and insulin resistance. However, it is still unclear whether cattle, like human and rodents, insulin resistance may reduce glucose utilization, in turn make fat mobilization increased, and then cause a vicious circle.

Our glucose tolerance test showed that some ketotic cows had insulin resistance, some did not, which is in accordance with a report that insulin resistance exits in some dairy cows with high blood body ketone $[12,14,17]$.

Our results demonstrated that dairy cows affected ketosis suffered from negative energy balance, liver disfunction, oxidative stress and decreased insulin sensitivity, implied that there may be a close relationship of insulin resistance and dairy ketosis, but it need further exploring the correlations among measurements in the insulin resistant and cows with ketosis in the future.

\section{Competing Interests}

The authors declare that they have no competing interests.

\section{Authors' contributions}

BW, CX and HYZ designed the study. BW and ZLS did the laboratory work. CX, ZLS and SS coordinated the writing and editing of the manuscript. All authors read and approved the final manuscript.

\section{Acknowledgements}

The authors thank financial support from the Chinese National Nature Science Foundation (31001094) and Chinese National Nature Science Foundation (2013BAD21B01-2 and 2012/BAD12B03-2).

\section{References}

1. As AN, Nazifi S, Ghasrodashti AR, Olyaee A (2011) Prevalence of subclinica ketosis in dairy cattle in the Southwestern Iran and detection of cutoff point for NEFA and glucose concentrations for diagnosis of subclinical ketosis. Prev Vet Med 100: 38-43.

2. Schönfeld P, Wojtczak L (2008) Fatty acids as modulators of the cellular production of reactive oxygen species. Free Radic Biol Med 45: 231-241.

3. Stern MP (1995) Diabetes and cardiovascular disease. The "common soil" hypothesis. Diabetes 44: 369-374.

4. Ceriello A, Motz E (2004) Is oxidative stress the pathogenic mechanism underlying insulin resistance, diabetes, and cardiovascular disease? The common soil hypothesis revisited. Arterioscler Thromb Vasc Biol 24: 816-823.

5. Turk R, Juretic D, Geres D, Svetina A, Turk N, et al. (2008) Influence of oxidative stress and metabolic adaptation on PON1 activity and MDA level in transition dairy cows. Anim Reprod Sci 108: 98-106.

6. Sharma N, Singh NK, Singh OP, Pandey V, Verma PK (2011) Oxidative stress and antioxidant status during transition period in dairy cows. J Anim Sci, 24 479-484

7. Abuelo A, Hernández J, Benedito JL, Castillo C (2013) Oxidative stress index (OSi) as a new tool to assess redox status in dairy cattle during the transition period. Animal 7: 1374-1378.

8. Holtenius $\mathrm{P}$, Holtenius $\mathrm{K}$ (2007) A model to estimate insulin sensitivity in dairy cows. Acta Vet Scand 49: 29

9. Ospina PA, Nydam DV, Stokol T, Overton TR (2010) Evaluation of nonesterified fatty acids and beta-hydroxybutyrate in transition dairy cattle in the northeastern United States: Critical thresholds for prediction of clinical diseases. J Dairy Sci 93: 546-554

10. Bouwstra RJ, Goselink RM, Dobbelaar P, Nielen M, Newbold JR, et al. (2008) The relationship between oxidative damage and vitamin $E$ concentration in blood, milk, and liver tissue from vitamin $\mathrm{E}$ supplemented and nonsupplemented periparturient heifers. J Dairy Sci 91: 977-987

11. Mazur A, Ayrault-Jarrier M, Chilliard Y, Rayssiguier $Y$ (1992) Lipoprotein metabolism in fatty liver dairy cows. Diabete Metab 18: 145-149. 
Citation: Xu C, Shu S, Xia C, Wang B, Zhang HY, et al. (2014) Investigation on the Relationship of Insulin Resistance and Ketosis in Dairy Cows. J Veterinar Sci Technol 5: 162. doi:10.4172/2157-7579.1000162

Page 4 of 4

12. Cebra CK, Garry FB, Getzy DM, Fettman MJ (1997) Hepatic lipidosis in anorectic, lactating holstein cattle: a retrospective study of serum biochemical abnormalities. J Vet Intern Med 11: 231-237.

13. Bionaz M, Trevisi E, Calamari L, Librandi F, Ferrari A, et al. (2007) Plasma paraoxonase, health, inflammatory conditions, and liver function in transition dairy cows. J Dairy Sci 90: 1740-1750.

14. Steen A, Grønstøl H, Torjesen PA (1997) Glucose and insulin responses to glucagon injection in dairy cows with ketosis and fatty liver. Zentralbl Veterinarmed A 44: 521-530.

15. Castillo C, Hernández J, Valverde I, Pereira V, Sotillo J, et al. (2006) Plasma malonaldehyde (MDA) and total antioxidant status (TAS) during lactation in dairy cows. Res Vet Sci 80: 133-139.

16. Liu GW, Zhang ZG, Wang JG, Wang Z, Xu C, et al. (2010) Insulin receptor gene expression in normal and diseased bovine liver. J Comp Pathol 143 258-261.

17. Zhang ZG, Li XB, Gao L, Li YF, Liu GW, et al. (2011) Serum antioxidant capacity of dairy cows with subclinical ketosis. Vet Rec 168: 22.

18. Holtenius $P$, Tråvén $M(1990)$ Impaired glucose tolerance and heterogeneity of insulin responses in cows with abomasal displacement. Zentralbl Veterinarmed A 37: 445-451. 